\title{
Improving Flow Measurement Accuracy Using a Portable Irrigation Turnout Calibration Unit
}

\author{
Stuart Styles, D.E. ${ }^{1}$, P.E. Kyle Feist, M.S, P.E. ${ }^{2}$, and Charles Burt, Ph.D., P.E. ${ }^{3}$
}

${ }^{1}$ Director. Irrigation Training and Research Center. California Polytechnic University, 1 Grand Ave., San Luis Obispo, CA 93407-0730; email: sstyles@calpoly.edu

${ }^{2}$ Irrigation Support Engineer. Irrigation Training and Research Center. California Polytechnic University, 1 Grand Ave., San Luis Obispo, CA 93407-0730; email: kfeist@calpoly.edu

${ }^{3}$ Chairman. Irrigation Training and Research Center. California Polytechnic University, 1 Grand Ave., San Luis Obispo, CA 93407-0730; email: cburt@calpoly.edu

\begin{abstract}
Relatively accurate flow measurement at irrigation district water delivery points is an important component of volumetric billing and equitable service. In California, this has often occurred with conversions to pressurized irrigation systems which commonly include the installation of pipeline flow meters as part of the on-farm system. However, a large portion of irrigation turnouts in the western US continue to operate via gravity and fall into one of the following categories: (a) a metergate, or similar structure was installed without adherence to standard construction requirements or (b) the structure was never intended for flow measurement.
\end{abstract}

For these and other scenarios, there is a need to efficiently calibrate turnouts in the field. While some in-situ calibration methods exist for open channel turnouts, they are rarely applied in the field for a variety of practical reasons.

After identifying this gap in field-practice, a special pump, or portable irrigation turnout Calibration Unit (Calibration Unit) was designed and constructed at the Cal Poly Irrigation Training and Research Center (ITRC). Within six weeks, thirty-two field turnout calibrations were performed using the Calibration Unit throughout seven California irrigation districts. Field testing protocol followed new guidelines developed by the USBR Mid Pacific Region and the California Department of Water Resources (DWR).

The results and analyses of these calibrations are presented in this paper. Practical applications, such as compliance with California regulations developed out of The Water Conservation Act of 2009 (SB X7-7) and constraints of this new calibration method are also discussed.

\section{INTRODUCTION}

Many farmers in the western US receive irrigation water from water user organizations (WUO) or districts. WUO of various types deliver water directly to farmers or community ditches at turnouts. The term turnout refers to a point of delivery where the ownership of water changes. As described in detail in (Feist and Burt, 2014) all turnouts serve two basic functions: (a) starting and stopping the flow of water and (b) Adjustment of the delivered flow rate. Advanced turnouts are capable of flow measurement and volumetric totalization, both of which are derived from direct manual or electronic measurements. 
In-field practices and the selection or installation of components providing turnout flow measurement and volumetric totalization vary widely with respect to each other and to welldocumented standards (USBR, 2001). As such, a wide range of measurement accuracies can be expected.

Additionally, not all measurements are effective. Effective turnout flow measurements can be characterized as (a) easy to understand and implement by operations staff, (b) actually implemented in the field, and (c) capable of providing relatively repeatable results.

In summary:

1. The capability for turnout flow measurement and volumetric totalization is not universal

2. Not all flow measurements are effective

3. There is a range of flow measurement and volumetric totalization accuracies

Background. Flow measurement has been practiced for thousands of years (AWWA, 1959) and is under continuous advancement. More recently, increased attention has been given to agricultural water flow measurement in California through the various programs and regulations designed to encourage water conservation and/or water delivery service equity. Some examples are provided in Table 1.

The activities listed in Table 1, among other market and on-farm factors, have generally increased the demand for accurate turnout flow measurement methods and devices. This increased demand has created a need to check the calibration of devices used for measurement.

More specifically, the demand for pipeline turnouts and pressurized irrigation systems has largely been satisfied by recent technological advances. Barriers to entry for farmers and irrigation districts have largely been meet through the proliferation of propeller, magnetic, ultrasonic and other metering technology. The majority of these meters can be characterized by the following; they are:

(a) Provided with traceability certificates from laboratory testing, exceeding most accuracy requirements (+/- 0.5 to $2 \%$ is a common benchmark for lab results)

(b) Relatively affordable and robust

(c) Easy to install, and to remove for re-calibration

(d) Available from a wide range of manufacturers and product lines

For these reasons, the continued expansion of pipeline flow meters for irrigation turnout flow measurement is no longer an engineering problem. That is not the case with open channel flow measurement. 
Table 1. Some examples of programs and regulations encouraging different levels of turnout flow measurement accuracy

\begin{tabular}{|c|c|c|c|c|}
\hline Entity & $\begin{array}{c}\text { Year } \\
\text { adopted }\end{array}$ & Program/Regulation & Requirements & Target Group \\
\hline $\begin{array}{l}\text { State Water Resources } \\
\text { Control Board } \\
\text { (SWRCB) }\end{array}$ & 2016 & $\begin{array}{c}\text { SB88 and State Water } \\
\text { Resources Control Board } \\
\text { Resolution NO. 2016-0005 }\end{array}$ & $\begin{array}{l}+/-10 \% \text { accuracy for large } \\
\text { turnouts } \\
+/-15 \% \text { accuracy for small } \\
\text { turnouts }\end{array}$ & $\begin{array}{l}\text { All diverters greater } \\
\text { than } 10 \mathrm{AF} \\
\text { All pre-1914 and } \\
\text { Riparian users }\end{array}$ \\
\hline $\begin{array}{c}\text { California Department } \\
\text { of Water Resources } \\
\text { (DWR) }\end{array}$ & 2009 & $\begin{array}{l}\text { SBx7-7 and subsequently } \\
\text { California Code of } \\
\text { Regulations (CCR) } 597\end{array}$ & $\begin{array}{c}\text { +/- } 12 \% \text { for existing } \\
\text { devices } \\
+/-10 \% \text { for new field } \\
\text { calibrated devices } \\
+/-6 \% \text { for new, laboratory } \\
\text { calibrated devices }\end{array}$ & $\begin{array}{l}\text { California irrigation } \\
\text { districts over } 25,000 \\
\text { acres and districts } \\
\text { between } 10,000 \text { and } \\
25,000 \text { acres with } \\
\text { adequate funding }\end{array}$ \\
\hline $\begin{array}{c}\text { Natural Resources } \\
\text { Conservation Service } \\
\text { (NRCS) }\end{array}$ & 2002 & $\begin{array}{c}\text { Farm Security and Rural } \\
\text { Investment Act - } \\
\text { Environmental Quality } \\
\text { Incentives Program (EQIP) }\end{array}$ & $\begin{array}{c}\text { Installation of a } \\
\text { measurement device with } \\
\text { an unspecified level of } \\
\text { accuracy }\end{array}$ & $\begin{array}{l}\text { All lands served by a } \\
\text { cost-share project }\end{array}$ \\
\hline $\begin{array}{c}\text { US. Bureau of } \\
\text { Reclamation (USBR) }\end{array}$ & 1993 & $\begin{array}{l}\text { Water Conservation } \\
\text { Criteria for Water } \\
\text { Management Plants - } \\
\text { Standard Criteria }\end{array}$ & $6 \%$ by volume & $\begin{array}{c}\text { Federal water } \\
\text { contractors }\end{array}$ \\
\hline
\end{tabular}

Open Channel Turnout Flow Measurement. “Standard” hydraulic structures or assemblies providing flow measurement are outlined in USBR (2001) along with clear operating instructions and construction recommendations. A common trait for the devices listed in the Water Measurement Manual, is that they are not manufactured in a factory, with few exceptions.

Instead most of the devices in operation at the irrigation district level were constructed on-site, making various negative outcomes plausible. For example, perhaps the original designer/builder:

1. Was not even aware of the construction standards

2. Had an insufficient understanding of the construction specifications

3. Adhered to the construction standards of the device itself, but the device operates under unsuitable hydraulic conditions

Lastly, another plausible outcome was that the device was constructed, sited and operated correctly, but suffers from a lack of maintenance. By listing these possibilities, it becomes apparent that a systematic evaluation of existing open channel turnouts fitted with "standard" flow measurement components might be prudent. Some California districts have already completed field investigations and cataloging processes (MID, 2015).

If a high rate of non-conforming "standard" measurement devices are located, a decision needs to be made between three choices:

1. In-situ calibration, or characterization and representative laboratory testing

2. Use a new flow measurement device. One common proposal is a permanently installed or portable flow Acoustic Doppler Velocity Meter (ADVM). One portable solution is described in Davids, et al (2012).

3. Replacement 
Options 2 and 3 listed above have quantifiable and perhaps substantial costs depending on the rate of non-conformance. Work specifically relating to Option 1 is presented in Feist and Burt (2014) and Howes and Burt (2016). This paper presents the continuing efforts in this area.

\section{CALIBRATION UNIT}

To facilitate verification of turnout flow measurement accuracies, a portable irrigation turnout Calibration Unit (Calibration Unit) was designed and constructed at the Cal Poly Irrigation Training and Research Center (ITRC). The Calibration Unit design was based on a previous, larger portable pump constructed by Sawtelle and Rosprim Machine Shop (Corcoran, CA) and described in Feist and Burt (2014). Major components of the new Calibration Unit include:

1. 20 foot bumper pull trailer

2. John Deere 74 HP Tier 4 Final diesel engine

3. Variable displacement hydraulic piston pump with Vernier cable control

4. Fixed displacement hydraulic motor

5. Cornell 14NHG Redi-Prime ${ }^{\mathrm{TM}}$, self-priming end suction pump; 12 CFS capacity.

6. A 16 inch and 12” McCrometer UM06 magnetic meters

7. A variety of 12 " aluminum and flexible suction and discharge pipe/hose

8. A custom low submergence suction housing

The engine is run at full RPM all the time, driving the special variable displacement hydraulic pump. The hydraulic pump drives the fixed displacement hydraulic motor, which in turn rotates the Cornell pump. This configuration allowed:

1. Full and fine adjustment of the Cornell pump speed (0-720 RPM) independent of the engine RPM.

2. The diesel engine to run at full RPM for peak torque all the time

The Calibration Unit is shown in Figure 1 under field test conditions.

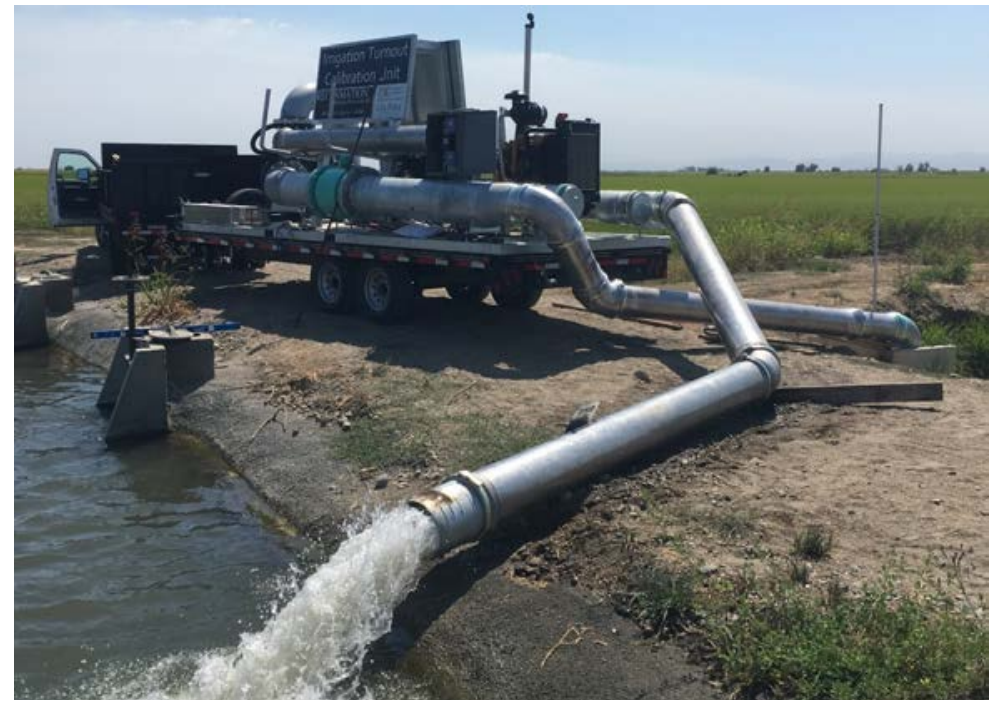

Figure 1. ITRC Calibration Unit in action at Glenn-Colusa Irrigation District 


\section{Improving Flow Measurement Accuracy Using a Portable Irrigation Turnout Calibration Unit \\ Before testing was conducted in the field, preliminary tests were conducted at the Cal Poly ITRC Water Resource Facility (WRF). Additionally, the completed Calibration Unit was calibrated using the National Institute of Science and Technology (NIST) traceable Weighing Tank also located at the WRF. The expanded uncertainty of the WRF Weighing Tank is estimated at +/- $0.1 \%$ using procedures outlined in NIST/SEMATECH (2012).}

Operations. As illustrated in Figure 2, the Calibration Unit would operate as follows:

1. Upon arrival to the turnout, initial turnout dimensions and notes were taken to characterize the turnout

2. A temporary dam is installed just downstream of the turnout in an open box, standpipe or ditch. Existing on-farm structures might be used in-lieu of a temporary dam if one exists at the turnout.

3. Water is delivered through the irrigation turnout. The water level downstream of the turnout is checked up by the temporary dam.

4. The Calibration Unit pump was ramped up to maintain the water level downstream of the turnout.

5. Pumped water passed through two, redundant magnetic meters integrated into the Calibration Unit's permanent piping

6. Pumped water was returned to the supply canal/lateral

7. Once the water level downstream of the turnout had stabilized (less than $+/-0.01 \mathrm{ft}$ over five minutes), the Calibration Unit pump flow rate is equal to the turnout flow rate. At that point in time, measurement data were collected.

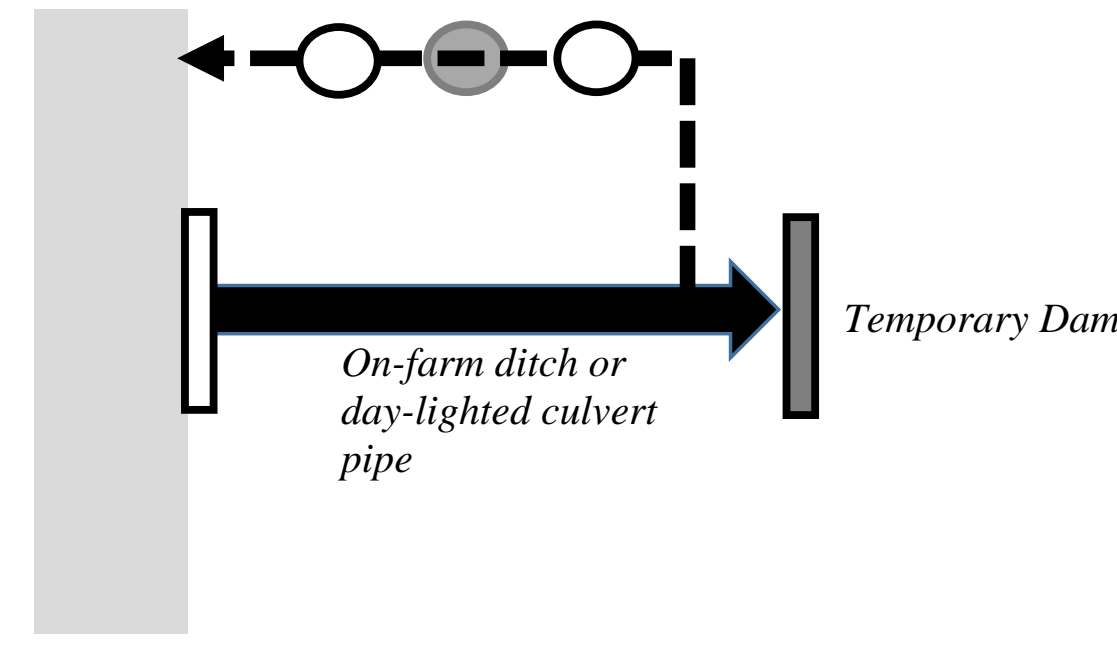

Supply Canal

(Upstream)

$\prod$ Turnout

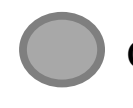

Calibration Unit pump

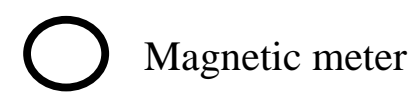

Figure 2. Conceptual schematic of the Calibration Unit operating in-the-field

Data Collection. Data were collected at three different turnout flow rates to represent minimum, average and maximum flow rates specific to the turnout being tested. 
At each of three different flow rates, two groups of data were manually collected after water level stabilization was achieved:

1. Measurands. Measurements required to estimate the turnout flow rate, using the most logical method for the specific turnout. For example, test data for a metergate would include (after a true gate zero and diameter were measured and recorded):
a. Upstream water measurement
b. Downstream water measurement
c. Net gate opening

2. Control. Equal to the average of 40 samples from the Calibration Unit magnetic meters (20 samples from each meter) taken over 5 minutes.

Additional data collection details:

- Any visual leaks across the temporary dam were estimated and accounted for

- Care was taken match typical irrigation water levels upstream and downstream of the turnout

- Initially, only a single set of turnout measurements were collected (e.g. one upstream level, one downstream level and one gate position for a metergate) at each flow rate. Later testing included turnout measurements at the beginning and end of the Control sampling to increase the confidence that no significant changes in water levels occurred while recording magnetic meter readings.

- All upstream and downstream measurements were taken from a common, level datum. Sometimes an existing concrete headwall was used, other times a four foot bubble level was propped up for a temporary level datum.

- The true gate zero was measured using a custom "hook" tool while the upstream side of the gate was submerged. Accuracy of this measurement is estimated at +/- 1/8"

- All dimensional data was taken using a measuring tape. In most cases, the accuracy of these measurements is estimated at $+/-1 / 8$ ".

\section{SUMMARY OF TESTS CONDUCTED AND ANALYSIS}

A total of 32 turnouts were tested throughout seven irrigation districts located around the San Joaquin and Sacramento Valleys. A summary of the tests conducted and turnout flow estimation methods are listed in Table 2.

Table 2. Calibration test summary from summer 2016

\begin{tabular}{|c|c|c|}
\hline Turnout Type & $\begin{array}{c}\text { Number of } \\
\text { turnouts tested }\end{array}$ & $\begin{array}{l}\text { Measurand Flow } \\
\text { Estimation Method }\end{array}$ \\
\hline Metergate & 23 & Metergate tables $^{1}$ \\
\hline Flashboard weir & 2 & ITRC weir stick \\
\hline $\begin{array}{l}\text { Round canal gate (no discharge pipe or downstream water measurement } \\
\text { port); Includes two metergates with non-functioning stilling wells }\end{array}$ & 5 & Metergate tables ${ }^{2}$ \\
\hline Propeller meter downstream of a single speed vertical turbine pump ${ }^{3}$ & 2 & Local display \\
\hline
\end{tabular}

${ }^{1}$ ITRC Water Measurement Tables from Burt and Howes (2016) were used when data was available (12", 18" and 24" round gates; 12" and 24" rectangular gates). Armco Water Measurement Tables (Armco, 1950) were used for all other gate sizes/types

${ }^{2}$ It is acknowledged that metergate discharge tables are not meant for estimated flow rates for simple canal gates. These tests were conducted to evaluate whether or not, by chance, one could achieve satisfactory results. Indeed, short of rating the gate (labor intensive), this seemed to be the most convenient option.

${ }^{3}$ Although turnouts with pumps are not "open channel", it was thought that the presenting the results regardless might be interesting for some readers 
Analysis Overview. A basic error analysis was conducted on the collected data. The general process for a single turnout flow rate is outlined below.

1. Estimate the measurand flow rate $\left(M_{Q}\right)^{1}$ by applying the turnout measurements to the flow estimation method listed in Table 2 corresponding to the test turnout.

2. Compute the control flow rate $\left(C_{Q}\right)$ by averaging all 40 samples of Calibration Unit magnetic meter readings.

3. Compute the absolute error $\left(E_{n}\right)$ using the equation below:

$$
\% \text { Absolute Error }=E_{n}(\%)=\left|\frac{M_{Q}-C_{Q}}{C_{Q}}\right| \times 100
$$

As mentioned previously, each complete turnout verification included testing at three different flow rates. Therefore, three different absolute error $\left(E_{n}\right)$ values were calculated for each turnout. Lastly, the average of all three absolute errors was calculated to simplify reporting.

The average absolute error $\left(E_{a}\right)$ was computed using the equation below:

$$
\% \text { Average Absolute Error }=E_{a}(\%)=\sum_{n=1}^{3}\left(E_{n}\right)=\sum_{n=1}^{3}\left(\left|\frac{M_{Q}-C_{Q}}{C_{Q}}\right| * 100\right)
$$

\section{RESULTS}

The test results are presented in this section in order, from an overview to more granular, starting with Table 3.

Table 3. Combined average of all results for each turnout category

\begin{tabular}{|c|c|c|c|c|}
\hline Turnout Category & $\begin{array}{c}\text { Propeller } \\
\text { meter }\end{array}$ & Metergate & Round canal gate & Weir \\
\hline $\begin{array}{c}\text { Combined average absolute error (all } \\
\text { individual flow tests) in \% }\end{array}$ & 1.0 & 8.9 & 12.6 & 9.5 \\
\hline
\end{tabular}

To get a sense of absolute error variability between individual flow tests, the data are presented in histograms (frequency distributions) below in Figure 3 through Figure 6.

\footnotetext{
${ }^{1}$ As mentioned previously in the paper, the data collection procedure was modified for about half of the turnouts tested to include two sets of turnout measurements - one at the start, a second data set at the end of the test. For these cases, $M_{Q}$ was computed using an average of each measurement pair.
} 
Improving Flow Measurement Accuracy Using a Portable Irrigation Turnout Calibration Unit www.itrc.org/papers/itcu.htm

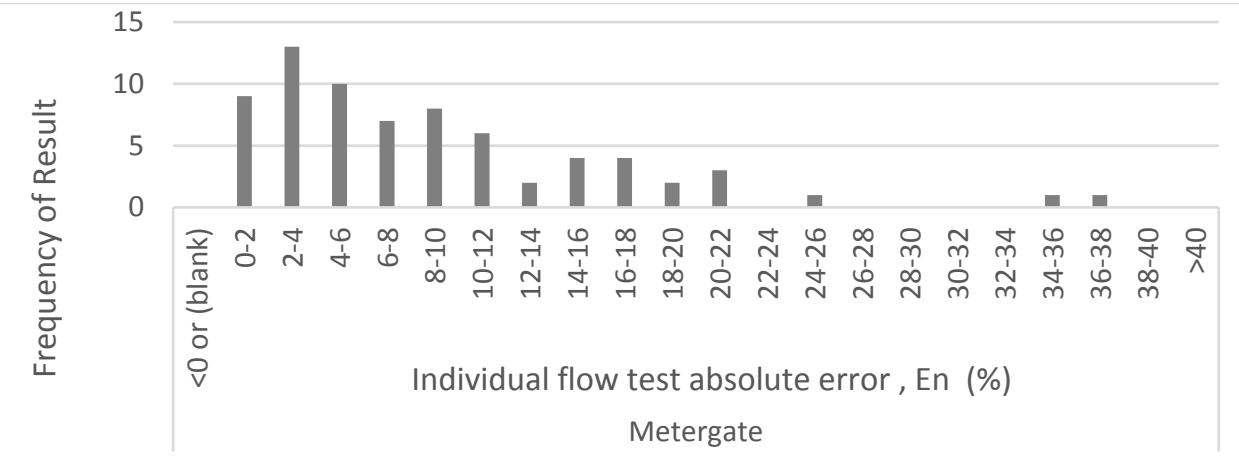

Figure 3. Frequency distribution of absolute error for all individual metergate flow tests

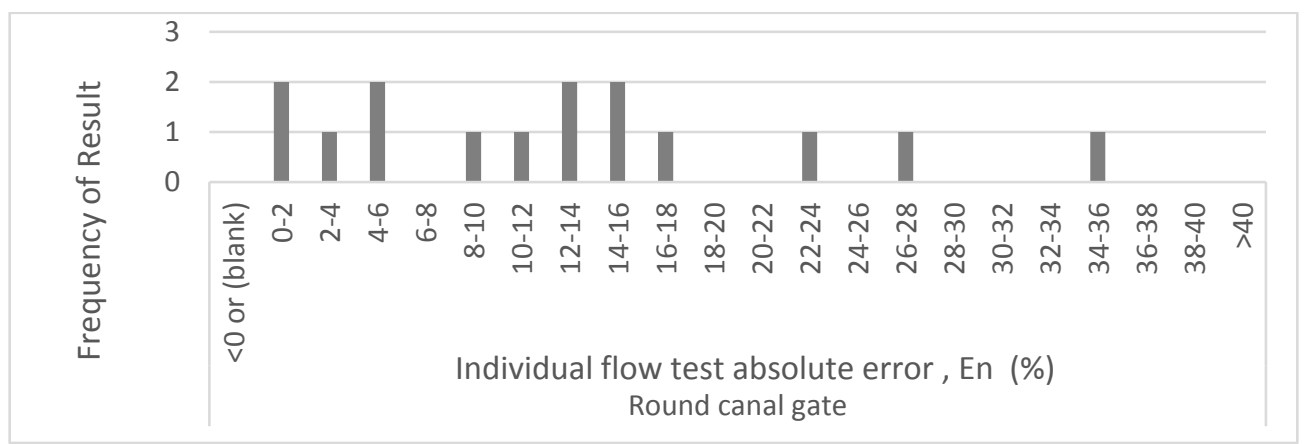

Figure 4. Frequency distribution of absolute error for all individual canal gate flow tests

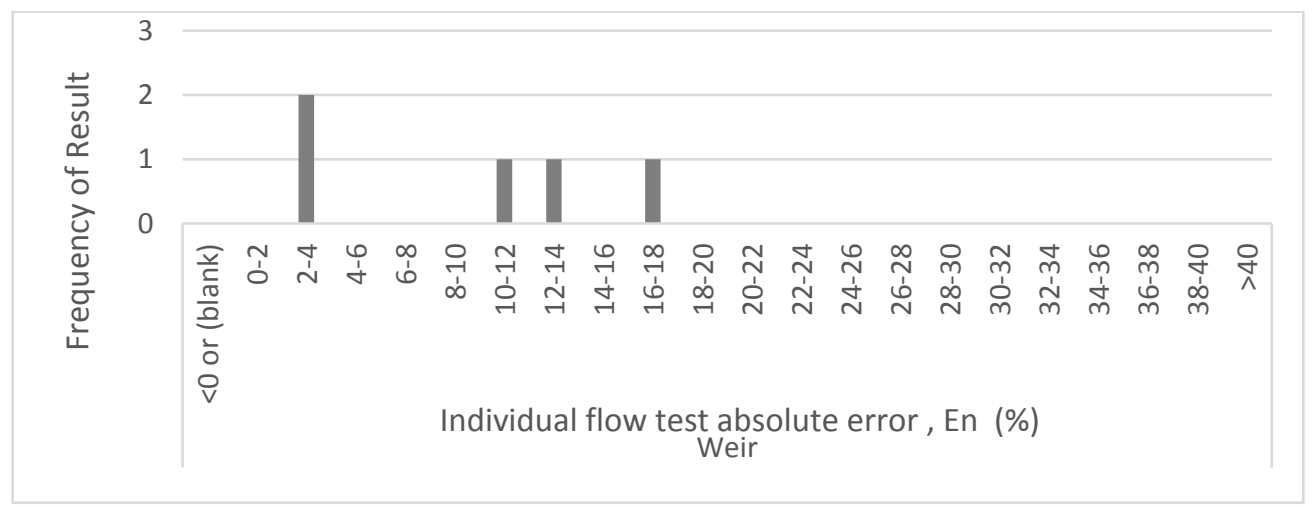

Figure 5. Frequency distribution of absolute error for all individual weir flow tests

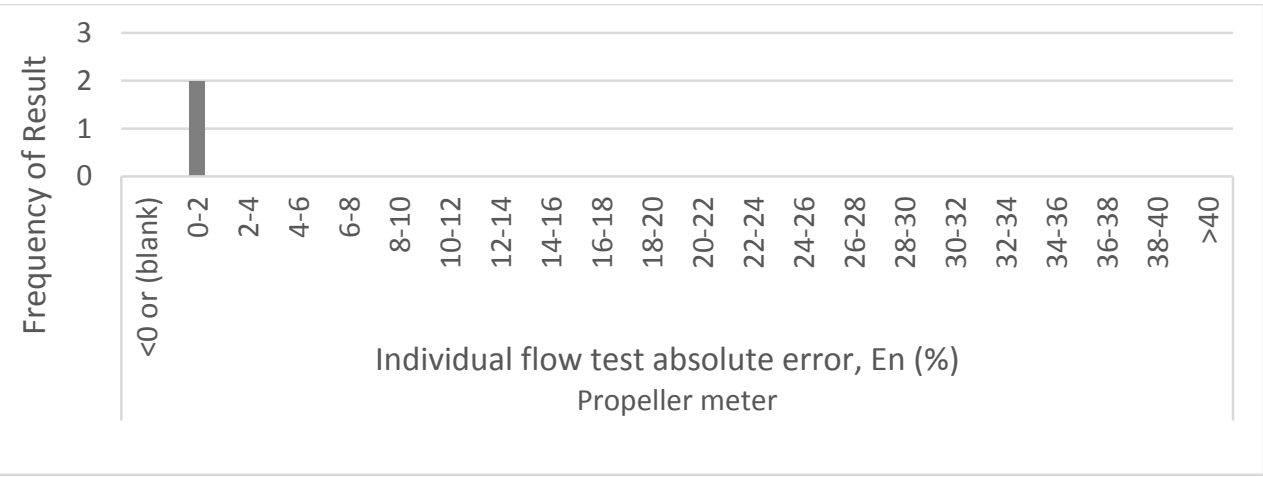

Figure 6. Frequency distribution of absolute error for all individual propeller meter flow tests 
Major Conclusions. Key points are presented below based on the results presented:

1. With the exception of the propeller meters tested, the flow tests results highlight substantial variability in absolute error.

2. The data supports the hypothesis that construction standards, hydraulic conditions and/or levels of maintenance are highly variable within and amongst irrigation districts

3. Six of the canal gate flow tests provided excellent flow measurement performance (less than or equal to $+/-6 \%$ ) using metergate rating tables. Still, using metergate tables to estimate the flow rate of a simple canal gate ${ }^{2}$ is not recommended without verification first.

4. Almost all of the weirs tested had poor hydraulic conditions - most of the flashboard weirs are installed inside of a standpipe with abrupt changes in flow paths. Additionally, the head measured upstream of the weir were small at the lower flow tests.

\section{ADDITIONAL METERGATE ANALYSIS}

The metergates tested in-the-field were categorized into groups with similar characteristics, such as age and construction technique. The categories are described in Table 4.

Table 4. Various categories of metergates with common characteristics

\begin{tabular}{|c|c|c|}
\hline $\begin{array}{c}\text { Metergate } \\
\text { category }\end{array}$ & Gate shape & Description \\
\hline 1 & Round & New pre-cast Briggs metergate headwalls with integrated stilling well and \\
Waterman canal gates
\end{tabular}

An extensive statistical analysis was not completed in this study, however the results of plotting histograms of the absolute error for individual flow tests produced interesting results, as illustrated in Figure 7 through Figure 9.

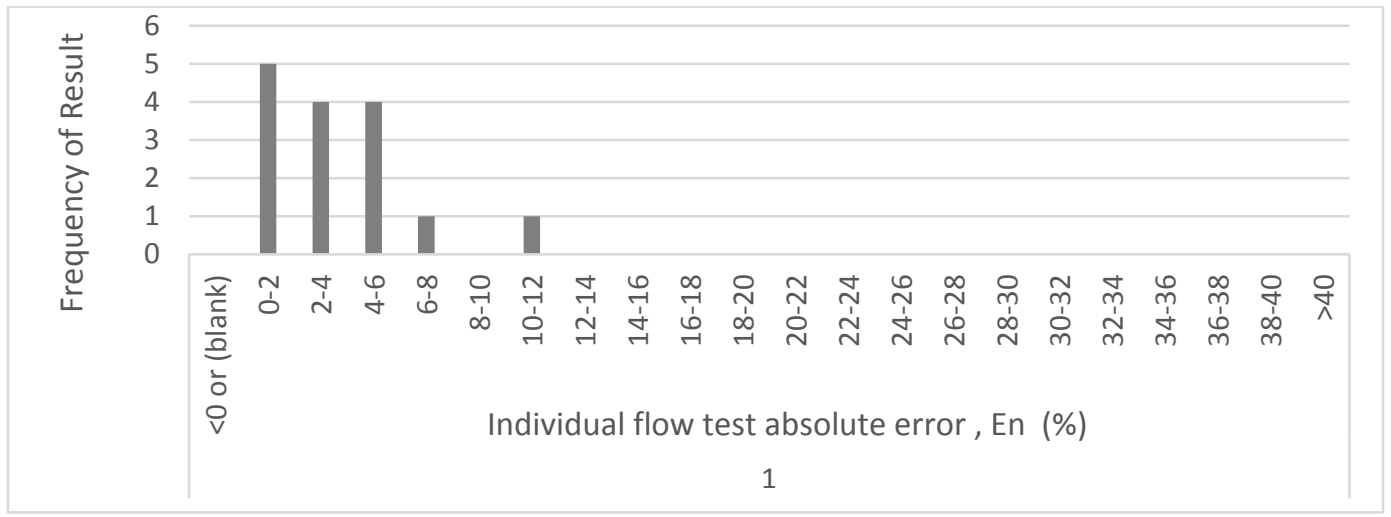

Figure 7. Frequency distribution of individual flow test results for Category 1 metergates (new, precast)

\footnotetext{
${ }^{2}$ Referring to any canal gate that fails to meet the requirements of metergates. That could include (a) no discharge pipe downstream of the canal gate, or (b) a missing or non-functional downstream water measurement port.
} 


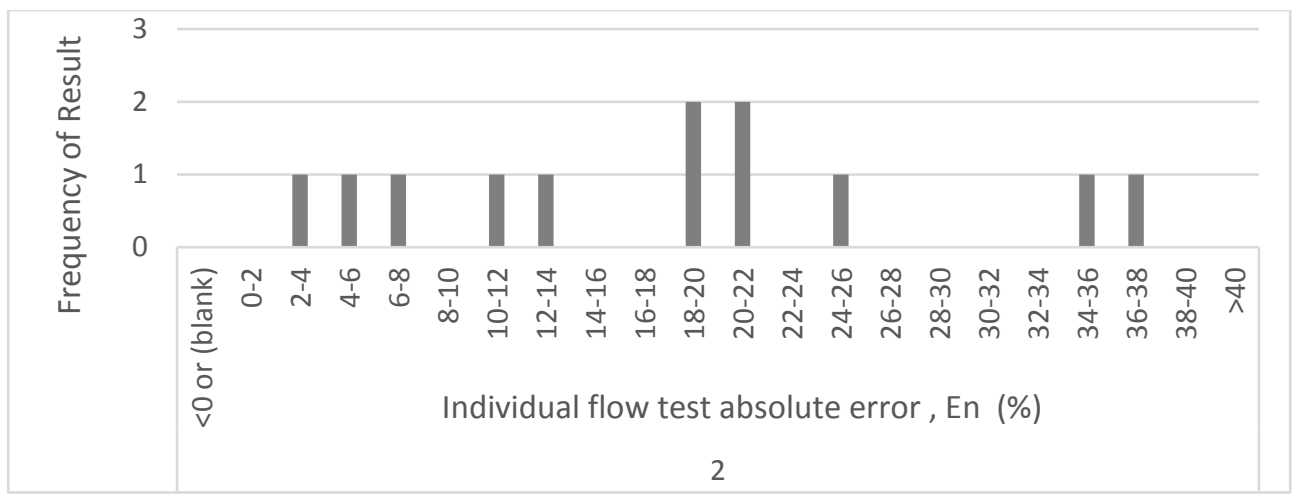

Figure 8. Frequency distribution of individual flow test results for Category 2 metergates (new, Mechanical Associates gates with small stilling wells)

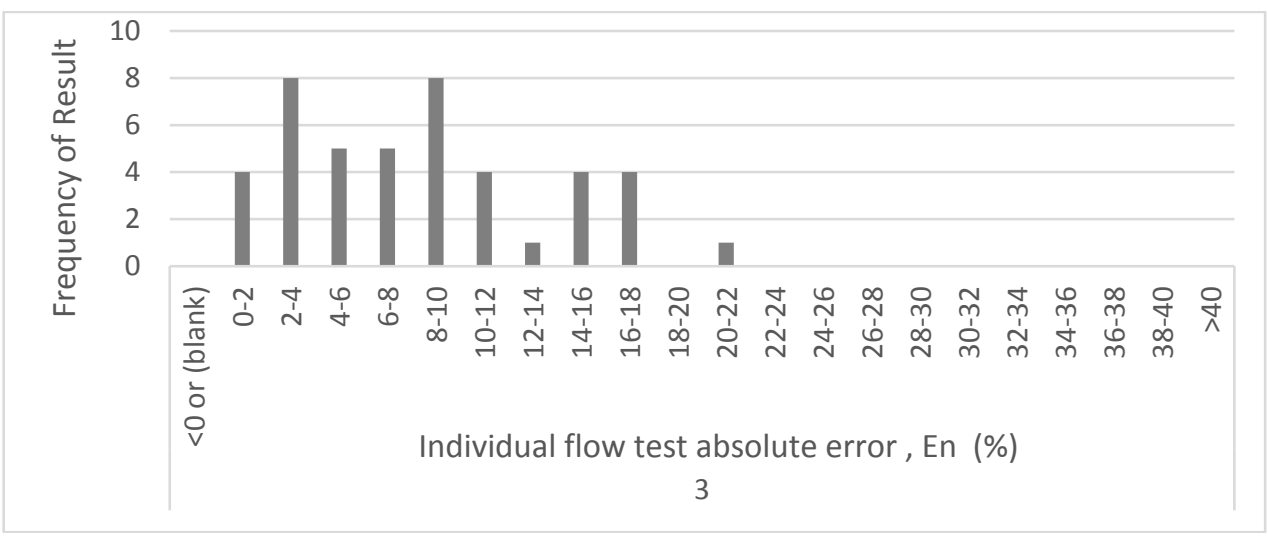

Figure 9. Frequency distribution of individual flow test results for Category 3 metergates (old, field assembled metergates)

Major Metergate Conclusions. Key conclusions:

1. All of the Category 1 metergates showed excellent flow measurement accuracies, with a narrow distribution. This is likely due to the following reasons:

a. All of the recommendations listed in Burt and Howes (2016) were followed in the fabrication and installation of the metergate components

b. The precast units are constructed in a factory and seem have excellent tolerances

2. Regarding Category 2 gates:

a. The lack of representative laboratory testing data is a non-starter for the uniquely shaped Mechanical Associates canal gates. Rating tables for round metergates were used in this study. Without a good rating table, correcting the other deficiencies listed below may not provide the expected flow measurement improvements.

b. The small (1" diameter) downstream measurement port and the lack of a stilling well are major sources of flow measurement error, because:

i. Turbulence is not dampened. Without a stilling well, the water surface inside the port can fluctuate considerably.

ii. The downstream water surface cannot be seen visually and therefore it is difficult to repeat or confirm downstream water measurements.

iii. The downstream measurement technique is inherently error prone. Field operators and the ITRC representatives in this study would use a rod that is 


\begin{abstract}
Improving Flow Measurement Accuracy Using a Portable Irrigation Turnout Calibration Unit
dusted and inserted into the port. When the rod is removed, the "water level" is identified as the point where the rod has been cleaned by water. The problem is that this technique only measures the highest downstream water level (lowest water level differential). Furthermore, the problem of measuring only the highest water level is compounded because of the fluctuating water level described in (a) above.
\end{abstract}

3. Category 3 gate performance is highly variable.

\title{
CALIBRATION UNIT COMMENTARY
}

Additional information and commentary regarding the Calibration Unit and calibration process is provided below:

1. A complete turnout calibration, including setup, three different flow tests and cleanup required an average of 6-7 person-hours (two well-trained operators for four hours). If the turnouts were available, two complete calibrations were achievable per day.

2. The operator training required is substantial. Although this was not a problem during the testing conducted for this paper, it could be difficult to find two persons accepting of a wide range of training and work including:

a. Driving a heavy trailer across the state

b. Operating heavy mechanical equipment

c. Understanding

i. Pumps and pipe hydraulics

ii. Some of the nuances of open channel and closed channel flow measurement

d. Maintaining a positive attitude and professionalism after months of California summer work

3. The operators needed to carry over 100 feet of 12 ” pipe/hose, numerous different angled fittings and operator creativity was a necessity for plumbing the pump in some cases.

4. A combination of factors enable the operators to pump as much as 5 CFS in less than 18” of total water depth without visual vortexing or audible cavitation:

a. A quality pump with low net positive suction head (NPSHa) - (about 7 feet)

b. Custom made suction "bells"

c. Sometimes floating plywood on the surface

d. Increased surface water velocities

In-Situ Turnout Calibration Alternatives. There are a variety of alternative methods for insitu turnout calibration, most commonly with no pump. Without a pump, the turnout must be irrigating during the calibration. This constraint has the following disadvantages for many California turnouts:

1. Throughout an entire year, more time is spent not irrigating. Any visit would need to be scheduled in advance.

2. Most irrigation events in the Central Valley divert a "constant" flow rate for a long period of time (6-18+ hours). Performing tests at a wide range of flow rates would require multiple return visits, also scheduled in advance

3. Scheduling visits during irrigations in advance would be difficult. Many farmers schedule deliveries with little advanced notice (hours to a day or so). 


\section{FUNDING}

All work performed by ITRC staff was funded via contract with the US Bureau of Reclamation Mid Pacific Region.

\section{ACKNOWLEDGEMENTS}

The authors would like to acknowledge the irrigation districts that participated in this study, which required staff commitments for field test support including. Without the support, this study would not have been possible. The participating districts include:

Banta Carbona Irrigation District

Glen-Colusa Irrigation District

Madera Irrigation District

Modesto Irrigation District

Patterson Irrigation District

San Luis Canal Company

West Stanislaus Irrigation District

The authors would also like to acknowledge the support of:

Cornell Pumps

McCrometer

Students of the Cal Poly BioResource and Agricultural Engineering Department

\section{REFERENCES}

AWWA (American Water Works Association). (1959) “AWWA Meter Manual. Journal (American Water Works Association).” Vol. 51, No. 6; June 1959. Pp. 791-799.

Burt, C.M. and D.J. Howes (2016). Practical Guide for Metergates (Rev. Nov 2016). California Polytechnic University; Irrigation Training and Research Center Report No. R 15-001

Davids, J.C., G. G. Davids, L.E. Blair, and E.A. Miller (2012). Creative, Accurate and CostEffective Farm-Gate Delivery Measurement Approaches. Proceedings of the USCID Water Management Conference: Managing Irrigation Systems in Today’s Environment. Reno, NV. November 13-16, 2014.

Feist, K.F and C.M. Burt (2014). Flow Measurement Options for Canal Turnouts. Proceedings of the USCID Water Management Conference; December 2-5, 2014. Denver, CO.

Howes, D.J. and C.M. Burt (2016). Accuracy of Round Meter Gates for On-Farm Deliveries. Journal of Irrigation and Drainage Engineering. Vol. 142, Issue 1 (January 2016)

MID. (2015). 2015 Agricultural Water Management Plant Update Draft: Modesto Irrigation District.

<http://www.mid.org/water/irrigation/documents/MID2015AgriculturalWaterManagementPl anDRAFT.pdf > (January 2017).

NIST/SEMATECH (2012). NEMA/SEMATECH e-Handbook of Statistical Methods.

$<$ http://www.itl.nist.gov/div898/handbook/> (January 2017).

USBR (2001). Water Measurement Manual: A Water Resources Technical Publication. U.S. Department of the Interior: Bureau of Reclamation. 